\title{
"Where Do We Go from Here?" Health System Frustrations Expressed by Patients with Multimorbidity, Their Caregivers and Family Physicians
}

«Où va-t-on maintenant? » la frustration face au système de santé telle que décrite par les patients en situation de multimorbidité, leurs aidants naturels et leurs médecins de famille

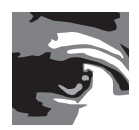

ASHLINDER GILL, HBSC

Graduate Student, Institute of Health Policy, Management E Evaluation, University of Toronto, Bridgepoint Collaboratory for Research and Innovation, Bridgepoint Active Healthcare, Toronto, ON

KERRY KULUSKI, MSW, PHD

Research Scientist, Bridgepoint Collaboratory for Research and Innovation, Bridgepoint Active Healthcare, Institute of Health Policy, Management E Evaluation, University of Toronto, Toronto, ON

LIISA JAAKKIMAINEN, MSC, MD

Department of Family and Community Medicine, Primary Care Research Unit, Sunnybrook Health Sciences Centre, Scientist, Institute for Clinical Evaluative Sciences, Toronto, ON

GAYATHRI NAGANATHAN, HBSC

Graduate Student, Institute of Health Policy, Management E Evaluation, University of Toronto, Toronto, ON

ROSS UPSHUR, MD, MSC

Bridgepoint Collaboratory for Research and Innovation, Bridgepoint Active Healthcare,

Department of Family and Community Medicine, Primary Care Research Unit, Sunnybrook Health Sciences Centre, Adjunct Scientist, Institute for Clinical Evaluative Sciences,

Dalla Lana School of Public Health, University of Toronto, Toronto, ON

WALTER P. WODCHIS, MA, MAE, PHD

Institute of Health Policy, Management E Evaluation, University of Toronto Adjunct Scientist, Institute for Clinical Evaluative Sciences Research Scientist, Toronto Rehabilitation Institute, Toronto, ON 


\begin{abstract}
Objectives: This study explored the care challenges experienced by older patients with multimorbidity, their informal caregivers and family physicians.

Approach: Semi-structured interviews were conducted with 27 patients, their informal caregivers and family physicians. Qualitative description was used to identify key themes in the interview transcripts.

Results: Participants experienced many common challenges when managing multimorbidity, including a lack of decision-making support, poor communication and uncoordinated health services. Within these themes, unique perspectives specific to the role of being a patient, caregiver or family physician emerged.

Conclusion: The study adds to a limited evidence base on the experience of patients with multimorbidity. By including the perspectives of their family caregivers and physicians, we provide important insight into the management of multimorbidity and recommend the uptake of specific strategies to address them.
\end{abstract}

\title{
Résumé
}

Objectif: Cette étude explore les défis vécus par les patients aînés en situation de multimorbidité, leurs aidants naturels et leurs médecins de famille.

Démarche: Des entrevues semi-dirigées ont été menées auprès de 27 patients, de leurs aidants naturels et de leurs médecins de famille. Les principaux thèmes des transcriptions des entrevues ont été dégagés à l'aide d'une description qualitative.

Résultats : Les participants éprouvent plusieurs défis communs dans la gestion de la multimorbidité, notamment un manque de soutien pour la prise de décision, de mauvaises communications et des services de santé non coordonnés. Parmi ces thèmes, il y a émergence de points de vue uniques propres aux rôles du patient, de l'aidant ou du médecin.

Conclusion: L'étude s'ajoute au peu de données fondées sur l'expérience des patients en situation de multimorbidité. En incluant les points de vue des aidants naturels et des médecins, nous apportons des pistes importantes pour la gestion de la multimorbidité et nous recommandons l'adoption de stratégies particulières pour aborder la question.

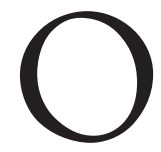

VER THE LAST 25 YEARS, THE PREVALENCE OF CHRONIC DISEASE HAS DOUBLED, while the proportion of individuals with four or more conditions has tripled (Uijen and van de Lisdonk 2008). With increasing age, the likelihood of being diagnosed with a chronic condition increases, as well as the number of functional limitations (Denton and Spencer 2010). Furthermore, the use of healthcare services and the number of chronic diagnoses also increase with age (Broemeling et al. 2008; Muggah et al. 2012).

Patients with multimorbidity typically require input from multiple providers across many care settings. If care is not properly coordinated, the quality of the care experience for patients 
“Where Do We Go from Here?” Health System Frustrations Expressed by Patients with Multimorbidity, Their Caregivers and Family Physicians

and their families can be frustrating at best and harmful at worst (Corser and Dontje 2011). Healthcare providers also experience challenges when providing care to persons with multimorbidity, given the lack of clinical practice guidelines that are available (Upshur and Tracy 2008). Much of the burden of day-to-day patient care falls to family caregivers as they engage in decision-making, monitor treatment adherence and coordinate care (Wolff 2012).

It is clear that healthcare system reform is needed, in particular, a shift from the current acute-focused model to one that encompasses chronic disease management and support for patients, their caregivers and care providers. Few studies have focused on the experience of persons with multimorbidity; the few that have tend to focus on the patient alone (Bayliss et al. 2008; Boyd et al. 2005; Loeb et al. 2003; Morris et al. 2011; Sinnott et al. 2013). Our team could identify no studies that compared and explored the challenges experienced by patients with multimorbidity, their informal caregivers and family physicians. Such a study would need to include all perspectives from the patient's circle of care to garner a full understanding of the management issues and appropriately address them. When creating primary care interventions for patients with complex chronic illnesses, a first step towards policy reform should be to understand the "core" of a patient's care team, which we define in this paper as the patient, the patient's informal caregiver and the family physician.

The objective of this study was to explore the challenges experienced by 27 patientcaregiver-family physician triads in an attempt to capture a full understanding of their health system experience and to illuminate where system improvements are most needed for managing multimorbidity.

\section{Methods}

\section{Data collection}

Eligible participants were recruited from a family health team within a tertiary academic health centre in Toronto, Ontario. Eligible patients were identified by their family physician by purposive sampling with the following inclusion criteria: 65 years of age or older, diagnosed with two or more chronic conditions, had an informal caregiver who participated in the patient's healthcare, spoke English as a first language and was able to provide informed consent. Within the family health team, a single family practice participated in the study, and consisted of four family physicians.

Two methods of patient recruitment were employed. Patients were first identified by the participating physicians during their team rounds from their patient rosters and using the study's inclusion criteria. If a patient had an upcoming clinic appointment, research associates ( $\mathrm{AG}, \mathrm{GN}$ ) were notified to attend the clinic to identify patients who might be interested in participating. After a patient's clinic visit, the primary care physician introduced the research study if the patient met the inclusion criteria, and was in good health to manage an interview. Once patients consented for participation, their informal caregivers and family physicians were also approached for participation. 
All members of the patient-caregiver-physician team had to agree to participate in order to be included in the study. If the primary care physician identified an eligible patient who was not being seen in clinic within the next month, administrative assistants phoned the patient at home, explained the research study and asked whether he or she would like to be contacted by a research associate to confirm his or her participation. The administrative assistants managed patient appointment scheduling and were considered a part of the clinical team.

Two research associates/co-authors (AG and GN) conducted the study interviews, either at a research office at the academic health centre or the patient's home, depending upon the patient's preference and ease of transportation. Interviews were conducted in English and took approximately 1.5 hours to complete. The physician and caregiver interviews took approximately 30 minutes to complete as their interview guides were shorter than the patient version. Only the interviewer and interviewee were present during the interviews. All interviews were conducted separately to ensure confidentiality of responses. The research associate read from a script prior to asking the interview questions, which consisted of an introduction of herself, a description of the study objectives and details about the informed consent process. The research associates took notes during and after the interviews, which served as secondary information if questions arose during thematic coding of the transcripts. Given the short time period for the study, transcripts were not returned to participants for comment. Interviews were digitally recorded, transcribed verbatim by an external source and checked for accuracy by the two research associates.

Semistructured interviews were conducted with all participants using an interview guide, designed by the Bridgepoint Collaboratory for Research and Innovation (Kuluski et al. 2013a), that consisted of both open- and closed-ended questions. This guide was piloted and adapted until deemed feasible for use with a complex patient population (Kuluski et al. 2013b; Kuluski et al. in press). The interview guide was adapted by the research team to include questions on care experiences within primary care, and more specifically, goals of care and frustrations experienced while managing multimorbidity.

This paper describes the themes of frustration experienced by patients with multimorbidity, their caregivers and family physicians when accessing care and meeting care goals. These themes were elicited by the questions, "Please describe any challenges you have had with accessing services in the past," and "Do you experience any frustration in achieving your health goals of care?"

\section{Data analysis}

Qualitative description was used to generate general summaries and emerging themes from participant interviews (Sandelowski 2000). Because the study was intended to capture the experiences of patients, caregivers and physicians, this approach was the most ideal for lowinference interpretation, as generating theory was not the purpose of analysis (Sandelowski 2000). Themes were derived inductively from the data and not identified in advance. Furthermore, transparency of methods and confirmability of themes were achieved by 
“Where Do We Go from Here?” Health System Frustrations Expressed by Patients with Multimorbidity, Their Caregivers and Family Physicians

frequent meetings and discussion of the themes until consensus was reached among three of the authors (AG, GN and KK). A detailed protocol and an audit trail of all decisions (Green and Thorogood 2009) were managed by the same three authors.

To ensure methodological rigour during data collection and analysis, the lead author (AG) consistently familiarized herself with the interview data by reading transcripts in their entirety for an initial understanding of key concepts and themes (Lathlean 2010). An initial coding scheme was developed by AG and verified by GN and KK after each researcher reviewed the first interview transcript in its entirety. Following that, data analysis was conducted simultaneously with data collection until saturation of themes occurred (i.e., when themes became repetitive within each of the patient, caregiver and physician groups). After 14 patient-caregiver-physician triads were interviewed, data were reviewed to develop an initial coding scheme. A final coding scheme was then developed for all patient, caregiver and physician transcripts after 28 triads were interviewed, as no new themes emerged.

\section{Results}

A total of 28 patient, informal caregiver and family physician triads were interviewed; however, only 27 triads were included for qualitative analysis, as one interview was incomplete (Table 1 ). Patients were on average 82.3 years of age ( \pm 7.7 years), mostly male $(56 \%)$ and diagnosed with a median of five chronic conditions $(\mathrm{SD}=2.43)$. Informal caregivers were on average 70.5 years of age ( \pm 11.3 years) and mostly female $(79 \%)$ spousal caregivers $(82 \%)$. Most patients and caregivers had more than high school education and lived in a single-family home.

TABLE 1. Participant characteristics

\begin{tabular}{|c|c|c|c|c|c|c|c|}
\hline Patient & $\begin{array}{l}\text { Age } \\
\text { (years) }\end{array}$ & Sex & $\begin{array}{l}\text { Number of } \\
\text { reported health } \\
\text { conditions* }\end{array}$ & Caregiver & $\begin{array}{l}\text { Caregiver } \\
\text { relationship to } \\
\text { patient }\end{array}$ & $\begin{array}{l}\text { Caregiver age in } \\
\text { years }\end{array}$ & Family physician \\
\hline $00 I P$ & 86 & Male & I & $00 I C$ & Wife & 77 & $00 \mid M$ \\
\hline $002 P$ & 79 & Male & 5 & $002 C$ & Wife & 77 & $00 \mid M$ \\
\hline 003P & 79 & Female & 4 & $003 C$ & Daughter & 53 & $00 \mid M$ \\
\hline 004P & 91 & Female & 4 & $004 C$ & Daughter & 59 & $00 \mid \mathrm{M}$ \\
\hline 005P & 77 & Male & 3 & $005 \mathrm{C}$ & Wife & 74 & $00 \mid M$ \\
\hline 007P & 85 & Female & 6 & $005 C$ & Daughter & 56 & $002 M$ \\
\hline 008P & 77 & Female & 12 & $008 \mathrm{C}$ & Husband & 80 & $003 M$ \\
\hline 009P & 82 & Male & 7 & $009 \mathrm{C}$ & Wife & 77 & $003 \mathrm{M}$ \\
\hline OIOP & 70 & Female & 5 & $010 \mathrm{C}$ & Sister & 75 & $003 \mathrm{M}$ \\
\hline $011 P$ & 88 & Female & 2 & $011 \mathrm{C}$ & Friend & 80 & 003M \\
\hline $012 \mathrm{P}$ & 83 & Female & 2 & $012 \mathrm{C}$ & Daughter & 50 & $00 \mid \mathrm{M}$ \\
\hline $013 P$ & 68 & Male & 2 & $013 \mathrm{C}$ & Wife & 68 & $00 \mid \mathrm{M}$ \\
\hline
\end{tabular}


TABLE 1. Continued

\begin{tabular}{|c|c|c|c|c|c|c|c|}
\hline Patient & $\begin{array}{l}\text { Age } \\
\text { (years) }\end{array}$ & Sex & $\begin{array}{l}\text { Number of } \\
\text { reported health } \\
\text { conditions* }\end{array}$ & Caregiver & $\begin{array}{l}\text { Caregiver } \\
\text { relationship to } \\
\text { patient }\end{array}$ & $\begin{array}{l}\text { Caregiver age in } \\
\text { years }\end{array}$ & Family physician \\
\hline $014 \mathrm{P}$ & 79 & Male & 4 & $014 \mathrm{C}$ & Wife & 58 & $004 M$ \\
\hline $016 \mathrm{P}$ & 85 & Male & 2 & $016 C$ & Wife & 91 & $004 M$ \\
\hline $017 \mathrm{P}$ & 84 & Male & 3 & $017 \mathrm{C}$ & Wife & 84 & $004 M$ \\
\hline $019 P$ & 75 & Female & 8 & $019 C$ & Husband & 73 & $004 M$ \\
\hline O2OP & 93 & Female & 5 & $020 C$ & Daughter & 58 & $004 M$ \\
\hline 023P & 91 & Female & 4 & 023C & Son & 62 & $003 M$ \\
\hline 024P & 88 & Male & । & $024 \mathrm{C}$ & Wife & 88 & $001 \mathrm{M}$ \\
\hline 025P & 80 & Male & 4 & $025 \mathrm{C}$ & Wife & 74 & $001 \mathrm{M}$ \\
\hline 026P & 67 & Male & 4 & $026 C$ & Wife & 65 & $00 \mid \mathrm{M}$ \\
\hline 027P & 73 & Female & 5 & $027 \mathrm{C}$ & Husband & 77 & $001 \mathrm{M}$ \\
\hline 028P & 81 & Female & 6 & $028 \mathrm{C}$ & Husband & 71 & $001 \mathrm{M}$ \\
\hline 030P & 83 & Male & 5 & 030C & Wife & 79 & $004 M$ \\
\hline $032 \mathrm{P}$ & 87 & Male & 8 & $032 \mathrm{C}$ & Wife & 87 & $004 M$ \\
\hline 033P & 94 & Male & 4 & 033C & Daughter & 61 & $002 M$ \\
\hline 034P & 96 & Male & 8 & 034C & Daughter & 63 & $004 M$ \\
\hline $035 P$ & 84 & Male & 5 & $035 \mathrm{C}$ & Daughter & 58 & 002M \\
\hline
\end{tabular}

* As a part of the inclusion criteria, patients with more than one health condition were identified by physicians or administrators. However, two of the patients reported only one health problem during the interview and were still included in the study.

Patients, their informal caregivers and family physicians expressed both system- and patient-level frustrations (Table 2). System-level challenges identified by participants included lack of efficient and timely information from healthcare providers and poor communication between care providers. Patient-level frustrations included challenges with managing multiple diseases and symptoms, and adherence to treatment recommendations. Table 2 outlines each of the system- and patient-level challenges and the participant who identified them.

TABLE 2. Patient, caregiver and physician themes

\begin{tabular}{|l|c|c|c|c|c|c|c|c|}
\hline & \multicolumn{3}{|c|}{ System-level challenges } & \multicolumn{3}{c|}{ Patient-level challenges } \\
\hline & $\begin{array}{l}\text { Poor } \\
\text { communication }\end{array}$ & $\begin{array}{l}\text { Lack of care } \\
\text { coordination }\end{array}$ & $\begin{array}{l}\text { Rotation } \\
\text { of medical } \\
\text { trainees }\end{array}$ & $\begin{array}{l}\text { Long } \\
\text { wait } \\
\text { times }\end{array}$ & $\begin{array}{l}\text { Access } \\
\text { to care }\end{array}$ & $\begin{array}{l}\text { Care } \\
\text { management }\end{array}$ & $\begin{array}{l}\text { Lack of } \\
\text { adherence }\end{array}$ & $\begin{array}{l}\text { No } \\
\text { frustration }\end{array}$ \\
\hline Patient & $\checkmark$ & $\checkmark$ & $\checkmark$ & $\checkmark$ & & $\checkmark$ & & \\
\hline $\begin{array}{l}\text { Informal } \\
\text { caregiver }\end{array}$ & $\checkmark$ & $\checkmark$ & & $\checkmark$ & & $\checkmark$ & $\checkmark$ & \\
\hline Physician & $\checkmark$ & $\checkmark$ & & $\checkmark$ & $\checkmark$ & $\checkmark$ & $\checkmark$ & $\checkmark$ \\
\hline
\end{tabular}


"Where Do We Go from Here?" Health System Frustrations Expressed by Patients with Multimorbidity, Their Caregivers and Family Physicians

\section{Frustrations expressed by patients}

Patients identified both system- and individual-level challenges: long wait times, poor communication, lack of care coordination, the rotation of medical trainees and personal care management.

\section{LONG WAIT TIMES}

Patients experienced long waits for appointments, which complicated their ability to manage their illnesses. For example, a patient who was managing high blood pressure, diabetes, arthritis, spinal stenosis and osteopoenia was challenged with long wait times for diagnostic testing:

I had to wait a long time for the MRI. Almost three-quarters of a year. Which I thought was excessive. And I had to wait about four months for the orthopaedic surgeon, who I found very gruff and not particularly helpful. [P027]

As patients waited for services and feedback, they had to contend with distressing symptoms.

\section{POOR COMMUNICATION}

Patients experienced poor communication with health providers and also witnessed poor communication between providers. A patient diagnosed with Crohn's disease, bladder cancer, hypertension and chronic obstructive pulmonary disease had difficulty obtaining feedback about the coordination of a specific procedure:

Well, it's not with the GI, it's with (specialist's name) and the GI guy. Like I need to know whether I can do this procedure. I think I can. So I'm going to try and nail (specialist MD's name) down as to the dates for it. [P013]

Similarly, a patient with cardiovascular disease, arthritis, depression and emphysema stated:

Well, I have frustrations if they don't follow up on tests. Because I think that if you go and have tests, ... someone should let you know if things are okay. [P008]

Another patient who was prone to seizures and diagnosed with diabetes, hypertension, prostatic hypertrophy and mild dementia noted that his specialists were failing to communicate with each other about a specific, distressing symptom:

And I've always thought of a cardiologist as being a person who doesn't worry just about your heart pressures but also about the swelling in my feet.... I just found out last fall that he thinks it's the problem of my family physician.... Anyway, these silos are almost like people are hard-wired into them. [P002] 
Not only did patients have to actively seek answers from their care providers; communication often broke down because providers did not communicate well with each other.

\section{LACK OF CARE COORDINATION}

Patients also noted poor coordination among providers when multiple medications had to be prescribed and various tests and procedures had to be coordinated. One patient attempted to schedule two imaging appointments from two different providers, but was hindered by the system's inability to coordinate the scans:

I tried to get the system to put the two scans together because they were the bladder and the aneurism. I was trying to eliminate two scans and have one do the job of both. First of all, (specialist MD's name) wouldn't do it. He wouldn't return my call, even. And then when I got on the table, when I went to the room that morning to get the CT scan, they said that they couldn't do it because it hadn't been asked for. [P002]

This example demonstrates that even when a patient is willing to coordinate his or her own care, and recognizes what is needed, the patient still falls victim to a fragmented system.

\section{ROTATION OF MEDICAL TRAINEES}

Communication and coordination were further hindered by the rotation of medical trainees within the family health team. Although patients understood that they were receiving care in a teaching hospital and there would be some interaction with trainees, they felt that there was too little oversight from their family physician. A patient who was recovering from surgery and had visual and auditory impairments, arthritis, and poorly controlled lipids shared the following:

I never have a problem getting in to see my GP (general practitioner) or getting an appointment to see a doctor, except that the doctor was often the resident.... They do not consult a doctor, you know, their superior when they should. So the frustration is with the residents taking on too much responsibility when they're not equipped to do so. But it's a teaching hospital, and this is part of being a patient there. [P007]

\section{CARE MANAGEMENT}

Patients experienced difficulties making decisions about their care, and were unsure how to prioritize and address competing health issues. A patient described earlier stated:

So I put the plan together: ... I've got to do the carotid artery first. I've got to do whatever I can about my lungs. ... It was (specialist's name) that I said this to, and he said that he had a plan. But I never thought he had a plan. [P002] 
"Where Do We Go from Here?" Health System Frustrations Expressed by Patients with Multimorbidity, Their Caregivers and Family Physicians

This example demonstrates that patients may feel alone when making decisions about their care. Furthermore, patients expressed uncertainty regarding their conditions, and were challenged to understand what was going on:

It's because I don't know what the answer is. I don't know what the problem is. And let's say that traditionally if there's a problem, I've always been geared to try and find out what's wrong and take corrective action. That's how I've lasted 88 years. [P024]

\section{Frustrations expressed by caregivers}

Caregivers also expressed challenges at the system level (long wait times, poor communication, lack of care coordination) and the patient level (care management).

\section{LONG WAIT TIMES}

Caregivers were often balancing their caregiving duties with full-time employment. Thus, long wait times even after an appointment was scheduled were frustrating for caregivers. Long waits also had a physical impact on patients:

She's 93, you know. So to go down and then sit in a waiting room for the doctor but it's a morning out of your life or an afternoon out of your week, [and] that is very tiring for her. [020C]

Similar to patients, caregivers expressed their frustration over long waiting periods for results and between appointments:

Usually it's just the waiting and waiting and waiting for the next appointment or results. ... So, like, nothing is happening. Whether they're attempting to communicate or not.... They had phoned him [husband] for the procedure and he said, no, you [patient/caregiver] have to talk to the other doctor because [husband] wasn't sure if he should have it. So silence as of now. And he's waiting for them to get coordinated and call him for the procedure. And I said good luck with that. [CG013]

Long wait times and lack of coordination between care providers made the organization of care challenging for caregivers.

\section{POOR COMMUNICATION AND LACK OF CARE COORDINATION}

Most caregivers were the primary organizers of care for the patient. They emphasized the need for a "point person" or single provider to manage the patient's care and to support communication and decision-making across the various specialties: 
You want the expert in a given area to be addressing a certain thing. You want the person that is best trained in that area. And there's no question about that. But somehow you want them also to look at the other aspects.... And that's hard to achieve because we do need the specialities. [CG020]

Caregivers recognized that family or specialist physicians did not always have up-to-date information, or were unaware of the patient's complete health history.

\section{CARE MANAGEMENT CHALLENGES AND LACK OF ADHERENCE}

Caregivers had the added challenge of managing patients who would not adhere to treatment recommendations. One caregiver noted:

No, not the system because it's mostly around his lack of - I think it's from depression, his lack of willingness to do these things that might have helped him along the road. His attitude is very negative, and that's frustrating to deal with. [CG009]

Noncompliance was often due to the patient's disease complexity and the difficulty of managing multimorbidity. A caregiver who managed all of her mother's care was struggling to address a particular distressing symptom:

Yes, there are some frustrations, but it's more to do with us knowing we can't achieve her goals $100 \%$. Like she needs better pain control, but we can't find a drug that won't give her side effects that will achieve the pain control she needs. Right? So she is choosing to have less pain control so that she can avoid the side effects that she doesn't like.... it's more the limitations of the medications that we currently have. That's my biggest frustration. [CG003]

Caregivers were also faced with making challenging decisions about whether a patient should undergo high-risk procedures such as an aneurism repair. Similar to patients, caregivers were frustrated about (and felt pressured) making the appropriate decisions; at times, they felt helpless upon recognizing that the situation was beyond their control.

\section{Frustrations expressed by family physicians}

Physician frustrations also fell into system- and patient-level themes. The system-level themes included lack of access to appropriate care, poor communication, long wait times and lack of care coordination. The patient-level themes included care management challenges and lack of adherence. 
“Where Do We Go from Here?” Health System Frustrations Expressed by Patients with Multimorbidity, Their Caregivers and Family Physicians

\section{LACK OF ACCESS TO APPROPRIATE CARE}

Family physicians noted that services were not always accessible to patients, resulting in unmet needs. For example, one family physician was frustrated about managing a patient with congestive heart failure as an outpatient:

When you have a patient in heart failure, it's incredibly frustrating to try to manage them as an outpatient. ... It's a huge health system issue. Like, she shouldn't have to go to the emergency department.... When you know that somebody is heading to emergency, there's a point where you could intervene before. And if there was a way to consult ... urgently, I think you could avoid a lot of hospitalizations. [004M_020P]

The same physician also struggled with how best to provide community care that would fulfill the patient's medical and social needs:

In general, it's probably true of everyone, that once they need CCAC, they don't seem to get as much as they really need. I mean that's true across the board. They'll come in for an hour a week and help you with a bath. And if you don't need help with a bath, they don't come in. So it's the patients who can bathe no problem, they can manage all their I(A)DLs, other ADLs, but they need help with their IADLs. They may need help with the food shopping. They may need help with food prep. That stuff is hard to get support for. [004M_035P]

It appears in these examples that family physicians were challenged with providing care and meeting patient needs in a timely way because of the organization of the healthcare system.

\section{POOR COMMUNICATION, LONG WAIT TIMES AND LACK OF CARE COORDINATION}

Similar to patients and caregivers, family physicians received little feedback from other healthcare providers involved in their patient's care and had to filter communication from multiple sources. Like patients and caregivers, family physicians also experienced delayed feedback from specialists:

Yes, thinking about her eyes, I actually don't think I get anything from her ophthalmologist.... So I don't really know what's going on with her eyes and what's going on with her driving. And I have to rely on her [patient]. [002M_007P]

The involvement of multiple specialists was a challenge for developing a care plan:

I think with her, like I said, too many cooks in the kitchen is sort of my frustration with her. Sometimes I think we're all sort of - I feel this with the specialists. Like, the physiatrist orders another test and another thing and another. And for what purpose? 
You know, I find we do too many investigations without standing back and asking her, "What do you want?" ... But then it's hard when they go see the specialist who starts going on, and then I get kyboshed. And then off we go into some I think we're doing some biological agent now, which is going to cause problems. [001M_P003]

When family physicians have many specialist physicians to collaborate with, they are challenged by the number of tests that are ordered and are not always clear on the rationale behind the investigations.

\section{CARE MANAGEMENT}

Managing multimorbidities was a common frustration expressed by providers, including how to provide support to the patient and the caregiver when the situation extended beyond their clinical control:

Do I have frustration? Yes, who doesn't? I mean, she's on coumadin for atrial fibrillation. So maintaining a therapeutic window appropriate for her is difficult. Her thyroid is difficult. And her constant need to drive at 92 with her progressive dementia is difficult because of her lack of understanding. I think any time you have a 92-year-old that is adamant that there's been an injustice - I'm frustrated because I can't help. ... You know, I think we're doing what we need to be doing. I'm just frustrated that I can't, you know, turn back the clock, change her vascular dementia, make her a better driver, to make her answer things, more importantly improve her executive functioning, cure her hypothyroidism. You know, aren't these frustrations of every family doctor? [003M_023P]

Physicians were unsure how to prioritize patient needs and felt that they lacked the appropriate resources to do so. Additional challenges included the management of difficult symptoms, the inability to prevent crises or acute exacerbations of the chronic disease and not being able to diagnose conditions rapidly when these were confounded by other diseases.

\section{LACK OF ADHERENCE}

Like caregivers, physicians were frustrated with patients' noncompliance with treatment. For example, a physician described a patient to be noncompliant when she declined community support, further distressing the informal caregiver:

But they're in crisis and she doesn't want to go to emerg. Or I've tried to convince her to allow other people to come in and help, and she declines. And then the daughter calls me like she's ready to kill herself. [002M_007P_007C] 
"Where Do We Go from Here?" Health System Frustrations Expressed by Patients with Multimorbidity, Their Caregivers and Family Physicians

Physicians did, however, recognize that the patient's disease complexity was a barrier to accepting supports and complying with treatment recommendations.

\section{NO FRUSTRATIONS}

Lastly, not all physicians were frustrated in providing patient care, particularly if the patient was stable, or if the patient-caregiver unit organized their own care:

No. I'd say no, from my perspective. ... More independent and driven, yes. He [patient] does a lot of my work for me in a sense. I mean he really does. I don't have to go at the specialists and nag at them. He does it for me. So that's great. Thank you. [001M_P002]

Interestingly, in the cases when physicians experienced little frustration, a substitution effect occurred whereby the burden of frustration appeared to shift to the patients and caregivers. This will be explored further in the discussion.

\section{Discussion}

Older patients, informal caregivers and family physicians experienced both system- and patient-level frustrations. These frustrations included poor communication from and between care providers, long wait times for appointments and feedback, making decisions about care and managing multiple diseases. Our findings align with previous research, including a study by Yen and colleagues (2011), who explored patient and provider perceptions of chronic care policies. These authors demonstrated that patients and providers both have competing demands in self-management practices, and require greater resources and access to chronic care. Similarly, Newcombe and colleagues (2010) described patient barriers to the selfmanagement of chronic disease, and also identified health system barriers such as care discontinuity and communication failures.

Our study adds to this evidence base by illuminating the perspectives and challenges within the patient-caregiver-physician triad and providing a full understanding of commonly identified issues. While the issues of communication, care coordination and wait times were more or less similarly articulated by all parties, some clear differences emerged, particularly in the involvement of medical trainees, the management of multimorbidity and treatment nonadherence. While patients and families recognized the necessity of training hospitals, they were frustrated by the sheer number of providers involved in their care, and the uncertainty exuded by individuals still in the early stages of their training. Our findings illuminated a potential trade-off between supporting medical trainees in their respective roles while also providing continuous, patient-centred care from familiar and consistent providers, especially since older persons with multimorbidities desire care coordination from a single source (Bayliss et al. 2008). Having a care manager act as a "point person" who can support both trainees and patients may begin to ameliorate this challenge. 
More specifically, even though patients, caregivers and physicians were similarly frustrated by not having appropriate answers or the ability to manage medical issues and symptoms, the issue of treatment nonadherence was articulated only by caregivers and physicians. Disease complexity often hindered treatment adherence and increased difficulty for the caregiver-physician team to manage the patient. Providing the appropriate treatment plan while considering the patient's limitations is essential. Furthermore, protecting patient autonomy while also providing needed support is a difficult but necessary balance to achieve. Finding ways to engage patients in determining an appropriate level of support without diminishing their sense of independence is required and should be the subject of further investigation.

Interestingly, some family physicians also reported not having any frustrations while organizing care for their patient. In this case, it appeared that the organization of care shifted to the patient-caregiver dyad, who in turn had to assume the brunt of the issues encountered. This finding has important implications for future research and chronic disease self-management. Patients and caregivers who take an active role in their care may in fact end up bearing the burden of their care without needed formal support and guidance. Finding the appropriate balance between formal support and self-management of conditions is not easy and requires further analysis.

Many of the challenges identified by patients, their caregivers and physicians were interrelated and often exacerbated each other. For example, poor communication among the care team delayed decision-making and increased wait times for feedback and appointments. Frustrations with managing the disease and patient adherence were further aggravated by the system's inability to support decision-making and provide the appropriate solutions for resolving health crises. Therefore, we elaborate on facilitating better communication, easing care transitions and coordination, and improving the management of multimorbidity and decisionmaking to better guide health policy for multimorbidity care. In the section that follows, we provide examples from the literature on ways to address these key challenges illuminated in our findings.

\section{Communication}

Timely access to, and clear feedback from, specialists was a need that was articulated by patients, caregivers and physicians. Interventions to ameliorate these challenges have been piloted and implemented. An Ontario-based pilot project facilitates timely referrals for specialty care using an electronic consultation system as an alternative to face-to-face consultations (Liddy et al. 2013). Patients in this program experienced improved access to specialist care and reduced wait times, as family physician-users are able to receive rapid replies to clinical questions, clarify the need for diagnostic tests or treatments and determine whether a face-to-face consultation is required. Specialist physician-users also expressed improved collaboration and communication with family physicians and improved appropriateness of referrals (Liddy et al. 2013). E-referral programs may offer an opportunity to enhance 
“Where Do We Go from Here?” Health System Frustrations Expressed by Patients with Multimorbidity, Their Caregivers and Family Physicians

communication, reduce wait times for people with multimorbidities and increase the ease of managing complex patients.

\section{Care transitions and coordination}

Family physicians, caregivers and patients also noted issues with care coordination and were confused about the role of different providers. Innovative clinical interventions that bring a holistic interprofessional, person-focused approach are required. Chouinard and colleagues (2013) conducted a pragmatic trial by applying a case management approach to managing complex chronic diseases. The intervention targeted persons with multimorbidities who were frequent users of acute care services. The intervention was led by a nurse within a primary care practice who worked as part of an interdisciplinary team. She regularly followed up with patients and provided them with self-management support (Chouinard et al. 2013). Another example is the Geriatric Resources for Assessment and Care of Elders (GRACE) model, which is an interdisciplinary case management model that links older persons with high needs to a designated nurse and social worker who communicate regularly with the patient's family physician (Counsell et al. 2007). Similarly, the Guided Care model of Boult and colleagues (2008) is led by a nurse who develops an integrated care guide designed to meet the unique circumstances of patients and their caregivers. The Guided Care nurse monitors the patient's needs, encourages self-management, provides support and education to caregivers, and coordinates the patient's care between providers and across care boundaries (Boult et al. 2008). Models of care such as these encourage greater patient and family participation, as well as decision-making support through intensive involvement of a multidisciplinary team including specialist physicians.

\section{Improving the management of multimorbidity and decision-making}

Fundamental to managing multimorbidities is decision-making support for patients, their caregivers and care providers. Few clinical practice guidelines are available to family physicians to address the needs of seniors with complex chronic conditions. Clinical practice guidelines for primary care are often developed for single diseases and aren't applicable to patients with multimorbidities (Boyd et al. 2005; Tinetti et al. 2004; Upshur and Tracy 2008). Persons with multimorbidities tend to require expert input from several providers to manage their illnesses. Balancing much-needed specialist input and whole-patient care is challenging and requires further attention. Tracy and colleagues (2013) developed a multidisciplinary primary care clinic for community-dwelling seniors with complex healthcare needs called the Interprofessional Model of Practice for Aging and Complex Treatment (IMPACT). In this model, patients and their caregivers actively participate in a comprehensive assessment and are given decisionmaking support by a multidisciplinary team including specialists. These examples highlight strategies that can be adopted to support patients, their caregivers and family physicians in the management of multimorbidities. 


\section{Limitations}

Study participants were predominantly Caucasian, English-speaking and sampled from a single family practice in an affluent urban setting. Thus, the transferability of our findings may be limited to patients who fit this demographic profile.

\section{Conclusion}

By asking patients, caregivers and family physicians to share their frustrations, the study unveiled important system- and patient-level issues from three critical perspectives. The inclusion of the perspectives of key members of the patient's circle of care provides triangulation of evidence on issues that can be comprehensively understood and potentially better managed.

\section{Acknowledgements}

The project was funded by the Ontario Ministry of Health and Long-Term Care, Health System Performance Research Network Grant. The views expressed in this paper are the views of the authors and do not necessarily reflect those of the funder. The authors gratefully acknowledge the Health System Performance Research Network and Project Manager Jessica Goncalves for supporting the study reported in this paper. The researchers extend their gratitude to the physicians, family caregivers, patients and staff at the Sunnybrook Family Health Team (Toronto, ON) for their time and dedication to the project reported in this paper.

Correspondence may be directed to: Ashlinder Gill, Research Assistant, Bridgepoint Collaboratory for Research and Innovation, 14 St. Matthews Road, Toronto, ON M4M 2B5; tel.: 416-461-8252 ext. 2902; fax: 416-461-0656; e-mail: gillashi@mail.utoronto.ca.

\section{References}

Bayliss, E.A., A.E. Edwards, J.F. Stiener and D.S. Main. 2008. "Processes of Care Desired by Elderly Patients with Multimorbidities." Family Practice 25: 287-93.

Boyd, C.M., J. Darer, C. Boult, L.P. Fried, L. Boult and A.W. Wu. 2005."Clinical Practice Guidelines and Quality of Care for Older Patients with Multiple Comorbid Diseases: Implications for Pay for Performance." Journal of the American Medical Association 294(6): 716-24.

Boult, C., L. Karm and C. Groves. 2008. “Improving Chronic Care: The ‘Guided Care' Model.” The Permanente Journal 12(1): 50-54.

Broemeling, A., D.E. Watson and F. Prebtani. 2008. "Population Patterns of Chronic Health Conditions, Co-morbidity and Healthcare Use in Canada." Healthcare Quarterly 11(3): 71-78.

Chouinard, M.C., C. Hudon, M.F. Dubois, P. Roberge, C. Loignon, E. Tchouaket et al. 2013. "Case Management and Self-Management Support for Frequent Users with Chronic Disease in Primary Care: A Pragmatic Randomized Controlled Trial." BMC Health Services Research 13: 49.

Corser, W. and K. Dontje. 2011. “Self-Management Perspectives of Heavily Comorbid Primary Care Adults." Professional Care Management 16(1): 6-15.

Counsell, S.R., C.M Callahan, D.O. Clark, W. Tu, A.B. Buttar, T.E. Stump et al. 2007."Geriatric Care Management for Low-Income Seniors: A Randomized Controlled Trial." Journal of the American Medical Association 298(22): 2623-33. 
“Where Do We Go from Here?" Health System Frustrations Expressed by Patients with Multimorbidity, Their Caregivers and Family Physicians

Denton, F.T. and B.G. Spencer. 2010. “Chronic Health Conditions: Changing Prevalence in an Aging Population and Some Implications for the Delivery of Healthcare Services." Canadian Journal on Aging 29(1): 11-21.

Green, J. and N. Thorogood. 2009. Qualitative Methods for Health Research (2nd ed.). London: Sage Publications.

Kuluski, K., C. Bensimon, C. Alvaro, A. Schaink, R. Lyons and R. Tobias. In press. “Life Interrupted: A Qualitative Exploration of the Impact of Complex Chronic Disease on the Daily Lives of Patients Receiving Complex Continuing Care." Illness, Crisis and Loss.

Kuluski, K., A. Gill, G. Naganathan, R. Upshur, L. Jaakkimainen and W.P. Wodchis. 2013a. "A Qualitative Descriptive Study on the Alignment of Care Goals Between Older Persons with Multimorbidities, Their Family Physicians and Informal Caregivers." BMC Family Practice 3(14): 133.

Kuluski, K., S.N. Hoang, A.K. Schaink, C. Alvaro, R.F. Lyons, R. Tobias et al. 2013b. “The Care Delivery Experience of Hospitalized Patients with Complex Chronic Disease." Health Expectations 16(4): e111-23. doi: 10.1111/hex.12085.

Lathlean, J. 2010. “Qualitative Analysis." In K. Gerrish and A. Lacey, eds., The Research Process in Nursing (6th ed.). Chichester: Wiley-Blackwell.

Liddy, C., M. Rowan, A. Afkham, J. Maranger and E. Keely. 2013.“Building Access to Specialist Care through e-Consultation." Open Medicine 7(1). Retrieved April 10, 2014. <http://www.openmedicine.ca/article/ view/551/492>.

Loeb, S.L., J. Penrod, S. Falkenstern, S.H. Gueldner and L.W. Poon. 2003."Supporting Older Adults Living with Multiple Chronic Conditions." Western Journal of Nursing Research 25(1): 8-29.

Morris, R.L., C. Sanders, A.P. Kennedy and A. Rogers. 2011. “Shifting Priorities in Multi-Morbidity: A Longitudinal Qualitative Study of Patients' Prioritization of Multiple Conditions." Chronic Illness 7(2): 147-61.

Muggah, E., E. Graves, C. Bennett and D.G. Manuel. 2012."The Impact of Multiple Chronic Diseases on Ambulatory Care Use: A Population-Based Study in Ontario, Canada." BMC Health Services Research 12: 452.

Newcombe, A.P., K. McGrath, J.K. Covington, S.C. Lazarus and S.L. Janson. 2010.“Barriers to Patient-Clinician Collaboration in Asthma Management: The Patient Experience." Journal of Asthma 47(2): 192-97.

Sandelowski, M. 2000. “Whatever Happened to Qualitative Description?" Research in Nursing \& Health 23(4): 334-40.

Sinnott, C., S. McHugh, J. Browne and C. Bradley. 2013.“GPs' Perspectives on the Management of Patients with Multimorbidity: Systematic Review and Synthesis of Qualitative Research." BMJ Open. 3: e003610. doi: 10.1136/ bmjopen-2013-003610.

Tinetti, M.E., S.T. Bogardus Jr. and J.V. Agostini. 2004. "Potential Pitfalls of Disease-Specific Guidelines for Patients with Multiple Conditions." New England Journal of Medicine 351(27): 2870-74.

Tracy, C.S., S.H. Bell, L.A. Nickell, J. Charles and R.E. Upshur. 2013."The IMPACT Clinic: Innovative Model of Interprofessional Primary Care for Elderly Patients with Complex Health Care Needs." Canadian Family Physician 59(3): e148-55.

Uijen, A. and E. van de Lisdonk. 2008. "Multimorbidity in Primary Care: Prevalence and Trend Over the Last 20 Years." European Journal of General Practice 14(1): 28-32.

Upshur, R.E. and S. Tracy. 2008. “Chronicity and Complexity: Is What's Good for the Diseases Always Good for the Patients?" Canadian Family Physician 54(12): 1655-58.

Wolff, J.L. 2012."Family Matters in Health Care Delivery." Journal of the American Medical Association 308(15): 1529-30.

Yen, L., J. Gillespie, Y.H. Rn, M. Kljakovic, J. Anne Brien, S. Jan et al. 2011.“Health Professionals, Patients and Chronic Illness Policy: A Qualitative Study." Health Expectations 14(1): 10-20. 